\title{
Effect of natural polyphenols on thromboxane levels in children with Crohn's disease
}

\author{
Kolacek $\mathrm{M}^{1}$, Paduchova $\mathrm{Z}^{1}$, Dvorakova $\mathrm{M}^{1}$, Zitnanova $\mathrm{I}^{1}$, Cierna $\mathrm{I}^{2}$, Durackova $\mathrm{Z}^{1}$, Muchova $\mathrm{J}^{1}$ \\ Institute of Medical Chemistry, Biochemistry and Clinical Biochemistry, Faculty of Medicine, Comenius \\ University, Bratislava, Slovakia. jana.muchova@fmed.uniba.sk
}

\begin{abstract}
OBJECTIVES: The aim of this study was to investigate the relationship between thromboxane levels and oxidative stress in children with Crohn's disease (CD), and examine the effect of natural polyphenolic compounds on thromboxane levels.

METHODS: This study involved 14 children suffering from CD and 15 healthy controls. Patients were receiving the polyphenolic extract Pycnogenol for 10 weeks. Plasma levels of the static and dynamic forms of thromboxane B2 as well as their metabolite 11-dehydro thromboxane B2 in urine were determined.

RESULTS: In comparison to controls, CD patients had significantly higher levels of the static and dynamic

forms of thromboxane B2. Pycnogenol decreased the level of the dynamic form of thromboxane B2 after 10 weeks of administration.

CONCLUSIONS: Paediatric Crohn's disease is associated with higher thromboxane levels. Our results indicate that Pycnogenol administration reduces thromboxane levels, which may positively influence some clinical symptoms of CD such as thromboembolic episodes (Tab. 3, Ref. 49). Text in PDF www.elis.sk. KEY WORDS: Crohn's disease, oxidative stress, Pycnogenol, thromboxanes.
\end{abstract}

\section{Introduction}

Crohn's disease (Morbus Crohn; CD) is a nonspecific, chronic inflammatory disease of the gastrointestinal tract. Sections of the intestine affected by inflammation are separated by healthy gut sections. The disease is named after an American physician - gastroenterologist Burrill Bernard Crohn who characterized the disease in detail for the first time in 1932. Although the exact cause of CD is currently unknown, a number of genetic, immunological and environmental factors are taken into account. Symptoms of the disease include abdominal pain, diarrhoea, weight loss, stunted growth in children, anorexia, bloody stools, and fever. Disease activity in children is expressed by Paediatric Crohn's Disease Activity Index (PCDAI) (1). Values $\geq 30$ of the short form of PCDAI correspond to the disease's severe stage and values $<10$ correspond to a non-active state $(2,3)$.

The clinical manifestations of CD include bleeding into the intestine, which leads first to an amplified formation of throm-

${ }^{1}$ Institute of Medical Chemistry, Biochemistry and Clinical Biochemistry, Faculty of Medicine, Comenius University, Bratislava, Slovakia, and ${ }^{2} 2$ nd Pediatric Clinic of the Faculty of Medicine, Comenius University and Children's University Hospital, Bratislava, Slovakia

Address for correspondence: J. Muchová, RND, PhD, Institute of Medical Chemistry, Biochemistry and Clinical Biochemistry, Faculty of Medicine, Comenius University, Spitalska 24, SK-813 72 Bratislava, Slovakia. Phone: +421.2 .90119411$

Acknowledgement: The study was conducted with financial support from the Ministry of Health grant 2007/16-UK-01, Ministry of Education grants VEGA 1/4310/07 and 1/0224/08 and Mind and Health, civil association. Pycnogenol was kindly provided by Horphag Res. Ltd., Geneva, Switzerland. boxane A2 (TXA2) and then to an increase in the aggregability of thrombocytes and haemocoagulation (4-7). The parameters of PCDAI calculation take into consideration the haemocoagulation levels (1-3). TXA2 is released from thrombocytes and low concentrations are synthesized by the endothelial cells of blood vessels during inflammation.

High concentrations of cytokines formed during inflammation activate the membrane phospholipase A2 of thrombocytes which leads to a release of a substrate necessary for the synthesis of TXA2, arachidonic acid.

After interacting with receptors on the vessel wall and stimulating the aggregation of thrombocytes, TXA2 acts as a vasoconstrictor, which might lead to thrombotic embolism. In patients suffering from $\mathrm{CD}$, the risk of thrombus formation is elevated (5). TXA2 is a very unstable substance, undergoing nonenzymatic hydrolysis within thirty seconds and producing its inactive metabolite thromboxane B2 (TXB2). In consequence of its short half-life, TXB2 acts as a paracrine substance.

The determination of TXB2 level reliably reflects the amount of TXA2 formation. TXB2 is released from organism in urine in form of its metabolite 11-dehydro-TXB2 (11dTXB2). Therefore, it is better to test for this metabolite than directly for TXB2.

Natural dietary polyphenols reduce oxidative stress (OS) and inflammatory disorders. They are able to reduce inflammation by inhibiting signalling pathways in intestinal cells. They interfere with the induction of NF- $\mathrm{BB}$ and MAPK signalling pathways, as well as with the production of inflammatory mediators $(8,9)$, and exert a protective effect on the cardiovascular system (10). Many polyphenols are derived from natural food products. Thus, they are 
often considered safer than conventional pharmaceutical drugs and can be more easily integrated into lifestyle changes (11).

Pycnogenol (Pyc), aFrench maritime pine (Pinus pinaster) bark extract, is a well-characterised source of polyphenols. This extract is standardized to have $70 \pm 5 \%$ procyanidins. Pyc has important antioxidant and biomodulation effects. Effects of Pyc include inhibition of the transcription factor NF- $\mathrm{KB}(12,13)$ and cyclooxygenases $(14,15)$, reduction of hypertension caused by stimulation of endothelial NO synthase, inhibition of the angiotensin converting enzymes $(16,17)$, reduction in mutations $(18)$, alleviation of the symptoms of allergic asthma, thus reducing the need for medications $(19,20)$, attenuation of immune dysfunction (21) and an increased cardio-protective effect in the case of ischemicreperfusion injury (22). In an in vitro study with human colon cancer cells, fruit juices enriched with Pyc increased the antioxidant capacity of the cells, and are shown to have higher anti-inflammatory activity when compared to fruit juices without Pyc (23).

The aim of this study was to investigate the relationship between the Crohn's disease in children, thromboxane levels and oxidative stress and to determine the ability of natural polyphenolic compounds to affect the levels of thromboxanes.

\section{Material and methods}

\section{Subjects}

Overall, 15 paediatric patients diagnosed with $\mathrm{CD}$ (6 males, 9 females; age from 13 to 18 years) were recruited into our study. They were registered at the 2nd Paediatric Clinic of the Children's University Hospital in Bratislava. The control group consisted of 15 healthy children ( 7 males and 8 females; age 12 to 18 years). The protocol was approved by the Ethical Committee of the Children's University Hospital, Bratislava, Slovak Republic. The study was approved by the ethics committee of the Faculty of Medicine, Comenius University. Parents of all participants signed an informed consent.

Inclusion criteria: Patients with CD in remission state of disease on maintenance therapy with the immunosuppressor Imuran (azathioprine [6-(1-methyl-4-nitro-5-imidazolylthio)-purine]) were included in our project.

Exclusion criteria: Patients with abdominal abscess, bowel obstruction, active gastrointestinal bleeding or malnutrition as well as patients with acute viral or bacterial infections and other chronic inflammatory disease were excluded from the study.

A placebo group was not included in our project for ethical reasons. Patients treated with 5-aminosalicylic acid (5-ASA) had to stop taking this drug two weeks prior to the enrolment (run-in period) and during the next 12 weeks of the project. Similarly, the use of supplementary antioxidant therapy was ceased during this period. Patients selected for the project were on a standard diet.

After 2 weeks of run-in period, Pyc powder $(2 \mathrm{mg} / \mathrm{kg} / \mathrm{day})$ was administered in capsules to patients for the next 10 weeks. Patients were investigated for other two weeks after discontinuation of Pyc supplementation (wash-out period).

\section{Collection of samples}

Biological specimens (blood and urine) were collected from patients before the initiation of Pyc administration (time 0), and 5 and 10 weeks after the beginning of Pyc administration (times 5 and 10 , respectively), as well as 2 weeks after the discontinuation of Pyc administration (time 12). Blood samples were collected with anticoagulant hirudin, and blood plasma and red blood cells were obtained by centrifugation of blood ( 10 minutes at 1,200 g). The serum was obtained by standard procedure from blood centrifugation in absence of anticoagulant. Aliquoted biological samples were frozen for later investigation. Blood plasma and serum were kept at $-80{ }^{\circ} \mathrm{C}$, and urine at $-20{ }^{\circ} \mathrm{C}$ until analysis.

\section{Measurement of plasma thromboxanes}

The inhibitory effect of Pyc on TX biosynthesis was monitored by measuring TXB2 levels, a stable metabolite of TXA2. Briefly, an aliquot of hirudin-anticoagulated blood $(0.6 \mathrm{ml})$ was placed immediately in ice bath and supplemented with Laspal $(0.5 \mathrm{mM}$ ASA), then centrifuged $\left(3,000 \mathrm{~g} ; 10 \mathrm{~min} ; 4^{\circ} \mathrm{C}\right)$ to obtain plasma (for the measurement of baseline concentration of TXB2 (TXB2) $)_{0}$ ). Another portion of whole blood was either incubated at room temperature for $1 \mathrm{~h}$ ('static' model of TX generation; ST(TXB2) ${ }_{60}$ ) or agitated at room temperature for $1 \mathrm{~h}$ on a rotary mixer ('dynamic' model of TX generation, which mimics the situation of increased shear stress better than the static system; (DYN(TXB2) $)_{60}$ ). Then it was inhibited with Laspal (0.5 mM ASA) and processed, as described above. Following the separation (centrifugation at 3,000 g; $10 \mathrm{~min}$ ), the aliquots of the plasma were stored at $-80{ }^{\circ} \mathrm{C}$ until further analysis. TXB2 concentrations in plasma and 11-dTXB2 in urine were measured in duplicate samples by a commercial kit (Cayman Chemical Company, Michigan, USA). No purification of samples was required because different dilutions gave consistent results differing by $<20 \%$. Final results of TX levels were presented as an increase in TXB2 concentration for used protocols of TX generation: $\Delta$ (TXB2)ST or $\Delta(\mathrm{TXB} 2) \mathrm{DYN}$, calculated as $\Delta(\mathrm{TXB} 2)$ $\mathrm{ST}=\mathrm{ST}(\mathrm{TXB} 2)_{60}-(\mathrm{TXB} 2)_{0}$ and $\Delta(\mathrm{TXB} 2) \mathrm{DYN}=\mathrm{DYN}(\mathrm{TXB} 2)_{60}$ - (TXB2), respectively. $\triangle$ (TXB2)ST and $\triangle(\mathrm{TXB} 2) \mathrm{DYN}$ were expressed in $\mathrm{pg} / \mathrm{ml}$ and $11-\mathrm{dTXB} 2$ in urine in $\mathrm{pg} / \mathrm{mmol}$ of creatinine.

\section{Statistical analysis}

Data show departures from normality according to ShapiroWilk's test and are presented as a median and interquartile range (1st quartile - 3rd quartile). Non-parametric Mann-Whitney U test was used for comparing the data. Non-parametric analysis of variance (Kruskal-Wallis test) and the post hoc all-pairwise comparisons (Conover-Inman test) were employed for detailed multiple comparisons (more than two groups). The calculations were performed using the statistical software StatsDirect (StatsDirect Ltd., Cheshire, UK). The limit for statistical significance was set at $\mathrm{p}<0.05$.

\section{Results}

Of the original 15 patients enrolled, 14 completed the entire study. One patient withdrew from the study for social reasons. All remaining patients completed the study and did not report any adverse effects during the 12 -week investigational period. 


\section{Baseline characteristics of the patients}

Out of the $15 \mathrm{CD}$ patients, seven were without therapy and eight patients were taking immunosuppressant Imuran (azathioprine). The potential effect of Imuran treatment on the clinical status has been verified by statistical analysis of the difference between selected markers from patients with CD not taking Imuran. All patients were in remission (mean score of PCDAI was 3.93). The baseline characteristics for the patients' group and controls are shown in Table 1. Biochemical parameters have been described in our previous paper (14).

\section{Changes in thromboxane levels}

Unlike the controls, CD patients have significantly increased plasma levels of static and dynamic forms of TXB2 $(p=0.014$ and $\mathrm{p}<0.0001$, respectively) but the level of metabolite 11-dTXB2 in urine was not different from that in the controls. The administration of Pyc to the patients decreased the $\Delta$ (TXB2)ST level after 5 weeks $(p=0.039)$ as well as after 10 weeks $(p=0.017)$. Similarly, the concentration of $\triangle($ TXB2)DYN decreased after five and ten weeks of administration ( $p=0.061$ and $p=0.045$, respectively). For both parameters, we observed a trend towards baseline measurements after the washout period. In urine, we observed that after five weeks of Pyc administration there was an upward trend of 11-dTXB2 levels which became significant after ten weeks of administration $(\mathrm{p}=0.001)$. After the washout period, there was an insignificant trend of 11-dTXB2 elevation (Tab. 2).

\section{Tab. 1. Baseline characteristics of subjects.}

\begin{tabular}{lcc}
\hline Parameter & $\begin{array}{c}\text { Control } \\
(\mathrm{n}=15)\end{array}$ & $\begin{array}{c}\text { Crohn's disease } \\
(\mathrm{n}=14)\end{array}$ \\
\hline Age (years) & $13.92(12-18)$ & $16.33(13-18)$ \\
M : F & $7: 8$ & $6: 9$ \\
Duration of disease (years) & - & $3.53(1-10)$ \\
Height $(\mathrm{m})$ & $1.58 \pm 0.02$ & $1.66 \pm 0.02$ \\
Weight $(\mathrm{kg})$ & $49.63 \pm 2.60$ & $54.41 \pm 2.40$ \\
BMI $\left(\mathrm{kg} / \mathrm{m}^{2)}\right.$ & $19.66 \pm 0.94$ & $19.76 \pm 0.52$ \\
PCDAI & - & $3.93 \pm 0.46$ \\
CRP & $1.4 \pm 0.83$ & $13.35 \pm 3.59^{* *}$ \\
Platelets $\left(10^{\wedge} / \mathrm{L}\right)$ & $250.00 \pm 13.20$ & $321.86 \pm 22.63^{*}$ \\
\hline
\end{tabular}

Data presented as mean (range from-to) and mean \pm SEM, respectively; $n-$ number of subjects per group. $\mathrm{M}$ - male, F - female, BMI - body mass index, PCDAI - Paediatric Crohn's Disease Activity Index. Physiological value of PCDAI is less than $10(\leq 10)$. CRP - C-reactive protein, $* \mathrm{p}=0.013$ Crohn's disease vs control, $* * \mathrm{p}=$ 0.006 Crohn's disease vs control.
Tab. 3. Correlations of thromboxanes with selected parameters.

\begin{tabular}{|c|c|c|}
\hline & $\Delta$ (TXB2)ST [pg/ml] & $\Delta(\mathrm{TXB} 2) \mathrm{DYN}[\mathrm{pg} / \mathrm{ml}]$ \\
\hline PCDAI & $\begin{array}{l}r=0.687 \\
p=0.012\end{array}$ & $\begin{array}{l}r=0.603 \\
p=0.026\end{array}$ \\
\hline $\begin{array}{l}\text { TAC } \\
(\mathrm{mmol} / \mathrm{l}) \\
\end{array}$ & $\begin{array}{l}\mathrm{r}=-0.664 \\
\mathrm{p}=0.011\end{array}$ & $\begin{array}{l}\mathrm{r}=-0.551 \\
\mathrm{p}=0.048\end{array}$ \\
\hline $\begin{array}{l}\mathrm{SOD} \\
(\mathrm{U} / \mathrm{g} \mathrm{Hb})\end{array}$ & $\begin{array}{l}\mathrm{r}=-0.455 \\
\mathrm{p}=0.082\end{array}$ & $\begin{array}{l}\mathrm{r}=-0.609 \\
\mathrm{p}=0.026\end{array}$ \\
\hline $\begin{array}{l}\mathrm{GPX} \\
(\mathrm{U} / \mathrm{mg} \mathrm{Hb})\end{array}$ & $\begin{array}{c}\mathrm{r}=-0.549 \\
\mathrm{p}=0.028\end{array}$ & NS \\
\hline $\begin{array}{l}\mathrm{FBC} \mathrm{Fe} \\
(\mu \mathrm{mol} / \mathrm{ml})\end{array}$ & $\begin{array}{l}r=-0.456 \\
p=0.060\end{array}$ & $\begin{array}{l}\mathrm{r}=-0.518 \\
\mathrm{p}=0.054\end{array}$ \\
\hline $\begin{array}{l}\mathrm{TBC} \mathrm{Fe} \\
(\mu \mathrm{mol} / \mathrm{ml})\end{array}$ & $\begin{array}{c}\mathrm{r}=-0.462 \\
\mathrm{p}=0.058\end{array}$ & $\begin{array}{c}\mathrm{r}=-0.600 \\
\mathrm{p}=0.028\end{array}$ \\
\hline $\begin{array}{l}\text { Tran } \\
(\mathrm{g} / \mathrm{l})\end{array}$ & $\begin{array}{l}r=-0.525 \\
p=0.042\end{array}$ & $\begin{array}{c}r=-0.723 \\
p=0.010\end{array}$ \\
\hline
\end{tabular}

$\Delta$ (TXB2)ST - static form of thromboxane B2; $\Delta$ (TXB2)DYN - dynamic form of thromboxane B2; 11-dTXB2 - 11-dehydro thromboxane B2; CRP - high sensitive C-reactive protein; $\mathrm{FBC} \mathrm{Fe}$ - free binding capacity of iron; GPX - activity of glutathione peroxidase; $\mathrm{Hb}$ - haemoglobin; $\mathrm{NS}$ - nonsignificant; TAC - total antioxidant capacity of plasma; TBC Fe - total binding capacity of iron; Tran - transferrin; SOD - activity of superoxide dismutase

Correlations of thromboxane levels with parameters of inflammation and oxidative stress

We have also observed the following significant positive correlations of $\Delta$ (TXB2)ST and $\Delta$ (TXB2)DYN with PCDAI (Tab. 3). In addition, we found significant negative correlations of $\triangle$ (TXB2) ST and $\Delta$ (TXB2)DYN with total antioxidant capacity of plasma and activity of superoxide dismutase, but the activity of glutathione peroxidase negatively correlated only with $\Delta$ (TXB2)ST (Tab. 3). Significant negative correlations of $\Delta$ (TXB2)ST and $\Delta$ (TXB2) DYN were observed with free and total Fe binding capacity and transferrin (Tab. 3). We did not observe any significant correlation with 11-dTXB2.

\section{Discussion}

In this study we found that patients with CD have higher levels of both, static and dynamic forms of TXB2 compared to the controls, and that the thromboxane levels are positively correlated with PCDAI and negatively correlated with the total antioxidant capacity of blood, activity of antioxidant enzymes and parameters of iron metabolism. Ten weeks of Pyc administration reduced the level of TXB2 dynamic form in plasma and increased the level of 11-dTXB2 in urine.

Tab. 2. Level of plasma thromboxanes.

\begin{tabular}{|c|c|c|c|c|c|}
\hline \multirow{3}{*}{ Type of thromboxane } & \multirow{3}{*}{ Controls } & \multicolumn{4}{|c|}{ Crohn's disease patients } \\
\hline & & \multirow{2}{*}{ Baseline } & \multicolumn{3}{|c|}{ Weeks of Pyc administration } \\
\hline & & & 5 & 10 & 12 \\
\hline $\begin{array}{l}\Delta(\mathrm{TXB} 2) \mathrm{ST} \\
{[\mathrm{pg} / \mathrm{ml}]}\end{array}$ & $\begin{array}{c}106.71 \\
(62.9-163.2)\end{array}$ & $\begin{array}{c}219.96^{* *} \\
(135.2-891.9)\end{array}$ & $\begin{array}{c}132.28^{\# \#} \\
(74.4-438.7)\end{array}$ & $\begin{array}{c}135.35^{\# \#} \\
(64.3-377.6)\end{array}$ & $\begin{array}{c}195.13 \\
(114.7-304.8)\end{array}$ \\
\hline $\begin{array}{l}\Delta(\mathrm{TXB} 2) \mathrm{DYN} \\
{[\mathrm{pg} / \mathrm{ml}]}\end{array}$ & $\begin{array}{c}137.40 \\
(99.6-152.6) \\
\end{array}$ & $\begin{array}{c}697.01 * * * \\
(281.9-1661.2)\end{array}$ & $\begin{array}{c}566.22^{\#} \\
(230.7-1051.5)\end{array}$ & $\begin{array}{c}493.22^{\# \#} \\
(249.7-1009.3)\end{array}$ & $\begin{array}{c}671.79 \\
(302.4-1023.9)\end{array}$ \\
\hline $\begin{array}{l}\text { 11-dTXB2 } \\
\text { [ng/mmol Crea] }\end{array}$ & $\begin{array}{c}167.50 \\
(120.1-205.3)\end{array}$ & $\begin{array}{c}228.76 \\
(135.3-296.6) \\
\end{array}$ & $\begin{array}{c}330.11 \\
(244.5-560.8)\end{array}$ & $\begin{array}{c}356.12^{\# \#} \\
(236.1-509.3)\end{array}$ & $\begin{array}{c}262.11 \\
(225.5-527.9) \\
\end{array}$ \\
\hline
\end{tabular}

Values are presented as a median and interquartile range (1st quartile - 3rd quartile). $\Delta(\mathrm{TXB} 2) \mathrm{ST}-\mathrm{static}$ form of thromboxane B2, $\Delta(\mathrm{TXB} 2) \mathrm{DYN}-\mathrm{dynamic}$ form of thromboxane B2, 11-dTXB2 - 11-dehydro thromboxane B2, Crea - creatinine, $* * \mathrm{p}<0.05 \mathrm{CD}$ vs control, $* * * \mathrm{p}<0.01 \mathrm{CD}$ vs control, ${ }^{\#} \mathrm{p}<0.1$ Pyc vs baseline, ${ }^{\#} \mathrm{p}<0.05$ Pyc vs baseline (before Pyc administration), $n$ for $\mathrm{CD}=14, n$ for $\mathrm{C}=15$. 
Clinical manifestations of CD include intestinal bleeding, which leads first to an amplified formation of thromboxane A2 (TXA2) and then to an increase in the aggregability of thrombocytes and haemocoagulation (4-7). Platelet aggregation belongs to clinical symptoms included in the assessment of disease severity using PCDAI $(2,3)$. An increase in the production of thromboxane synthase and adhesion of thrombocytes to the intestinal wall are associated with a release of other mediators of inflammation and consequent deterioration of the patient's condition (25). A positive correlation between TXB2 and marker of inflammation (CRP) confirms the relationship between increased thrombocyte aggregation and inflammation.

Since inflammation is undoubtedly associated with oxidative stress, it is assumed that factors involved in the pathogenesis of CD include also OS $(27,28,36)$. Oxidative stress (redox stress) is defined as an imbalance between oxidants and antioxidants in favour of the former, resulting in significant damage to biomolecules, organs and whole organism $(29,30)$. Oxidative stress can be caused by both excessive production of reactive metabolites (oxidants) and compromised antioxidant defences. Oxidative stress may manifest in form of damaged lipids, proteins and DNA. Several products resulting from oxidative damage have been established as markers of oxidative stress. Unlike healthy individuals, CD patients have reduced plasma antioxidant capacity (31), and increased lipoperoxide levels (32), as well as advanced oxidation protein products (18). In addition, they have lower activities of antioxidant enzymes $(24,28,33,34)$, also during disease remission (35). The massive production of ${ }^{\circ} \mathrm{OH}, \mathrm{O}_{2}{ }^{-}$and subsequent lipoperoxidation are considered the main mechanism of oxidative damage to the intestinal wall (36). Lipoperoxidation also contributes to the increase in the formation of thromboxanes (37).

Several in vivo and ex vivo experiments have demonstrated that natural polyphenolic substances present in Pyc are able to reduce platelet aggregability $(15,38,39,40,41)$. It is assumed that the effects are based on enhanced endothelial NO synthase activity and subsequent release of NO (inhibiting the aggregation of thrombocytes) $(42,43)$. These effects of natural polyphenols may also originate from the inhibition of cyclooxygenase (COX) (14) as well as from the inhibition of inflammatory signalling pathways which are activated by NF- $\mathrm{kB}, \mathrm{MAP}$ kinase and myeloperoxidase $(12,35,44)$. According to our previous study, in an ex vivo environment, Pyc can inhibit thrombocyte aggregation (15). Pyc can also improve the function of the endothelium (45). As a result of the reduction in inflammation, the lipoperoxidation is reduced, which leads to a reduction in the concentration of isoprostanes and thromboxanes (46).

Recent studies demonstrate that standardized polyphenolic plant extracts from various natural sources decrease platelet aggregation, formation of thromboxane $\mathrm{A} 2$ and malondialdehyde, as well as inhibit both COX activity (47) and attenuated ADP-induced blood platelet aggregation $(48,49)$.

Our results indicate that Pycnogenol administration reduces blood thromboxane levels, which can positively influence some clinical symptoms of CD such as thrombosis formation.

\section{References}

1. Yoshida EM. The Crohn's Disease Activity Index, its derivatives and the Inflammatory Bowel Disease Questionnaire: a review of instruments to assess Crohn's disease. Can J Gastroenterol 1999; 13 (1): 65-73.

2. Hyams JS, Ferry GD, Mandel FS, Gryboski JD, Kibort PM, Kirschner BS, Griffiths AM, Katz AJ, Grand RJ, Boyle JT, Michener WM, Levy JS, Lesser ML. Development and validation of a pediatric Crohn's disease activity index. J Pediatr Gastroenterol Nutr 1991; 12 (4): 439-447.

3. Kappelman MD, Crandall WV, Colletti RB, Goudie A, Leibowitz IH, Duffy L, Milov DE, Kim SC, Schoen BT, Patel AS, Grunow J, Larry E, Fairbrother G, Margolis P. A short pediatric Crohn's disease activity index for quality improvement and observational research. Inflamm Bowel Dis $2011 ; 17$ (1): 112-117.

4. Baumgart DC. Crohn's Disease and Ulcerative Colitis: From Epidemiology and Immunobiology to a Rational Diagnostic and Therapeutic Approach. Springer Science \& Business Media New York City; 2012. p. 133-140.

5. Webberley MJ, Hart MT, Melikian V. Thromboembolism in inflammatory bowel disease: role of platelets. Gut 1993; 34: 247-251.

6. Tekelioglu Y, Uzun H, Sisman G. Activated platelets in patients suffering from inflammatory bowel disease. Bratisl Lek Listy 2014; 115 (2): 83-85.

7. Carty E, Nickols C, Feakins RM, Rampton DS. Thromboxane synthase immunohistochemistry in inflammatory bowel disease. J Clin Pathol 2002; 55: 367-370.

8. Romier B, Schneider YJ, Larondelle Y, During A. Dietary polyphenols can modulate the intestinal inflammatory response. Nutr Rev 2009; 67 (7): 363-378.

9. Rohdewald PJ. Pycnogenol, French maritime pine bark extract. In: Coates P, Blackman MR, Cragg G, Levine M, Moss J, White J, editors. Encyclopedia of Dietary Supplements. New York: Marcel Dekker; 2005. p. 545-553.

10. Jung MH, Seong PN, Kim MH, Myong NH, Chang MJ. Effect of green tea extract microencapsulation on hypertriglyceridemia and cardiovascular tissues in high fructose-fedrats. Nutr Res Pract 2013; 7 (5): 366-372.

11. Kim HS, Quon MJ, Kim JA. New insights into the mechanisms of polyphenols beyond antioxidant properties; lessons from the green tea polyphenol, epigallocatechin 3-gallate. Redox Biol 2014; 2: 187-195.

12. Grimm T, Chovanová Z, Muchová J, Sumegová K, Liptáková A, Ďuračková Z, Högger P. Inhibition of NF-אB activation and MMP-9 secretion by plasma of human volunteers after ingestion of maritime pine bark extract (Pycnogenol). J Inflamm 2006; 3:1.

13. Xia R, Ji Ch, Zhang L. Neuroprotective Effects of Pycnogenol Against Oxygen-Glucose Deprivation/Reoxygenation-Induced Injury in Primary Rat Astrocytes via NF-אB and ERK1/2 MAPK Pathways. Cell Physiol Biochem 2017; 42 (3): 987-998.

14. Schäfer A, Chovanová Z, Muchová J, Sumegová K, Liptáková A, Duuračková Z, Högger P. Inhibition of COX-1 and COX-2 activity by plasma of human volunteers after ingestion of French maritime pine bark extract (Pycnogenol). Biomed Pharmacother 2006; 60 (9): 5-9.

15. Golański J, Muchová J, Golański R, Ďuračková Z, Markuszewski L, Watala C. Does pycnogenol intensify the efficacy of acetylsalicylic acid in the inhibition of platelet function? In vitro experience. Postepy Hig Med Dosw (online) 2006; 60: 316-321.

16. Rohdewald P. A review of the French maritime pine bark extract (Pycnogenol), a herbal medication with a diverse clinical pharmacology. Int $\mathrm{J}$ Clin Pharmacol Ther 2002; 40 (4):158-168. 
17. MacKay D. Nutrients and botanicals for erectile dysfunction: examining the evidence. Altern Med Rev 2004; 9 (1): 4-16.

18. Križková L, Ďuračková Z, Krajčovič J. Natural polyphenols possess antioxidative and antimutagenic properties. 8. mezioborová česko-slovenská toxikologická konference; 2003 Sept 3-5; Praha. Praha: (s.n.), 2003; 128 p.

19. Belcaro G, Luzzi R, Cesinaro Di Rocco P, Cesarone MR, Dugall M, Feragalli B, Errichi BM, Ippolito E, Grossi MG, Hosoi M, Errichi S, Cornelli U, Ledda A, Gizzi G. Pycnogenol improvements in asthma management. Panminerva Med 2011; 53 (3 Suppl 1): 57-64.

20. Liu Z, Han B, Chen X, Wu Q, Wang L, Li G. Pycnogenol Ameliorates Asthmatic Airway Inflammation and Inhibits the Function of Goblet Cells. DNA Cell Biol. 2016; 35 (11): 730-739.

21. Lee J, Nam DE, Kim OK, Lee MY. Pycnogenol attenuates the symptoms of immune dysfunction through restoring a cellular antioxidant status in low micronutrient-induced immune deficient mice. Nutr Res Pract 2014; 8 (5): 533-538.

22. Xiao P, Zhang K, Tao Z, Liu N, Ge B. Cardioprotective effect of Pycnogenol in ischemic-reperfusion injury (IRI) in rats. Cell Mol Biol (Noisyle-grand). 2017; 63 (10): 49-53.

23. Frontela-Saseta C, López-Nicolás R, González-Bermúdez CA, PesoEcharri P, Ros-Berruezo G, Martínez-Graciá C, Canali R, Virgili F. Evaluation of antioxidant activity and antiproliferative effect of fruit juices enriched with Pycnogenol in colon carcinoma cells. The effect of in vitro gastrointestinal digestion. Phytother Res 2011; 25: 1870-1875.

24. 24 Koláček M, Muchová J, Dvořáková M, Paduchová Z, Žitňanová I, Čierna I, Országhová Z, Székyová D, Jajcaiová-Zedníčková N, Kovács L, Ďuračková Z: Effect of natural polyphenols (Pycnogenol) on oxidative stress markers in children suffering from Crohn's disease - a pilot study. Free Radic Res 2013; 47 (8): 624-34.

25. Rutella S, Vetrano S, Correale C, Graziani C, Sturm A, Spinelli A, De Cristofaro R, Repici A, Malesci A, Danese S. Enhanced platelet adhesion induces angiogenesis in intestinal inflammation and inflammatory bowel disease microvasculature. J Cell Mol Med 2011; 15 (2): 625-634.

26. Biasi F, Leonarduzzi G, Oteiza PI, Poli G. Inflammatory Bowel Disease: Mechanisms, Redox Considerations, and Therapeutic Targets. Antioxid Redox Signal 2013; 19 (14): 1711-1747.

27. Zhu H, Li YR. Oxidative stress and redox signaling mechanisms of inflammatory bowel disease: updated experimental and clinical evidence. Exp Biol Med 2012; 237 (5): 474-480.

28. Iborra M, Moret I, Rausell F, Bastida G, Aguas M, Cerrillo E, Nos P, Beltrán B. Role of oxidative stress and antioxidant enzymes in Crohn's disease. Biochem Soc Trans 2011; 39 (4): 1102-1106.

29. Sies H, editor. Oxidative Stress: Oxidants and Antioxidants. London; San Diego: Academic Press; 1991. 650 p.

30. Ďuračková Z. Free radicals and antioxidants for non-experts. In: Systems Biology of Free Radicals and Antioxidants. Berlin: Springer; 2014, p. 3-38.

31. Koutroubakis IE, Malliaraki N, Dimoulios PD, Karmiris K, Castanas E, Kouroumalis EA. Decreased total and corrected antioxidant capacity in patients with inflammatory bowel disease. Dig Dis Sci 2004; 49 (9): 1433-1437.

32. Wendland BE, Aghdassi E, Tam C, Carrrier J, Steinhart AH, Wolman SL, et al. Lipid peroxidation and plasma antioxidant micronutrients in Crohn disease. Am J Clin Nutr 2001; 74 (2): 259-264.

33. Phylactos AC, Fasoula IN, Arnaud-Battandier F, Walker-Smith JA, Fell JM. Effect of enteral nutrition on antioxidant enzyme systems and inflammation in paediatric Crohn's disease. Acta Paediatr 2001; 90 (8): 883-888.
34. Krzystek-Korpacka M, Neubauer K, Berdowska I, Zielinski B, Paradowski L, Gamian A. Impaired erythrocyte antioxidant defense in active inflammatory bowel disease: impact of anemia and treatment. Inflamm Bowel Dis 2010; 16 (9): 1467-1475.

35. Moura FA, de Andrade KQ, Dos Santos JCF, Araújo ORP, Goulart MOF. Antioxidant therapy for treatment of inflammatory bowel disease: Does it work? Redox Biol 2015; 6: 617-639.

36. Kruidenier L, Kuiper I, Lamers CBHW, Verspaget HW. Intestinal oxidative damage in inflammatory bowel disease: semi-quantification, localization, and association with mucosal antioxidants. J Pathol 2003; 201 (1): 28-36.

37. Praticó D, Pasin M, Barry OP, Ghiselli A, Sabatino G, Iuliano L, FitzGerald GA, Violi F. Iron-dependent human platelet activation and hydroxyl radical formation: involvement of protein kinase C. Circulation 1999; 99 (24): 3118-3124.

38. Nocun M, Uličná O, Muchová J, Ďuračková Z, Watala C. French maritime pine bark extract Pycnogenol reduces thromboxane generation in blood from diabetic male rats. Biomed Pharmacother 2008; 62 (3): 168-172.

39. Araghi-Niknam M, Hosseini S, Larson D, Rohdewald P, Watson RR. Pine bark extract reduces platelet aggregation. Integr Med 2000; 2 (2): 73-77.

40. Pütter M, Grotemeyer KHM, Würthwein G, Araghi-Niknam M, Watson RR, Hosseini S, Rohdewald P. Inhibition of smoking induced platelet aggregation by aspirin and pycnogenol. Thromb Res 1999; 95 (4): $155-161$.

41. Hubbard GP, Wolffram S, Lovegrove JA, Gibbins JM. The role of polyphenolic compounds in the diet as inhibitors of platelet function. Proc Nutr Soc 2003; 62 (2): 469-478.

42. Nishioka K, Hidaka T, Nakamura S, Umemura T, Jitsuiki D, Soga J, Goto C, Chayama K, Yoshizumi M, Higashi Y. Pycnogenol, French Maritime Pine Bark Extract, Augments Endothelium-dependent Vasodilation in Humans. Hypertens Res 2007; 30 (9): 775-780.

43. Xiaoping Du. New mechanism for nitric oxide- and cGMP-mediated platelet inhibition. Blood 2007; 109: 392-393.

44. Mochizuki M, Hasagewa N. Therapeutic Efficacy of Pycnogenol in Experimental Inflammatory Bowel Diseases. Phytother Res 2004; 18 : 1027-1028.

45. Enseleit F, Sudano I, Périat D, Winnik S, Wolfrum M, Flammer AJ, Fröhlich GM, Kaiser P, Hirt A, Haile SR, Krasniqi N, Matter CM, Uhlenhut K, Högger P, Neidhart M, Lüscher TF, Ruschitzka F, Noll G. Effects of Pycnogenol on endothelial function in patients with stable coronary artery disease: a double-blind, randomized, placebo-controlled, cross-over study. Eur Heart J 2012; 33 (13): 1589-1597.

46. Lee J, Nam DE, Kim OK, Lee MY. Pycnogenol attenuates the symptoms of immune dysfunction through restoring a cellular antioxidant status in low micronutrient-induced immune deficient mice. Nutr Res Pract 2014; 8 (5): 533-538.

47. Bijak M, Saluk-Bijak J. Flavonolignans inhibit the arachidonic acid pathway in blood platelets. BMC Complementary and Alternative Medicine 2017; 17: 396.

48. Luzak B, Kassassir H, Rój E, Stanczyk L, Watala C, Golanski J. Xanthohumol from hop cones (Humulus lupulus L.) prevents ADP-induced platelet reactivity. Arch Physiol Biochem 2017; 123 (1): 54-60.

49. Ginter E, Simko V, Panakova V. Antioxidants in health and disease. Bratisl Lek Listy 2014; 115 (10): 603 - 606.

Received June 28, 2019. Accepted July 3, 2019. 